GABA-GABA: Jurnal Pengabdian Masyarakat

dalam bidang Pendidikan Bahasa dan Seni

Vol. 1 No. 2, November 2021, Hal 65-73

e-ISSN : 2797-8494

\title{
LITERASI INFORMASI LINTAS BUDAYA KUNCI KESUKSESAN BERBASIS DARING (KOLABORASI DOSEN DAN ALUMNI)
}

\author{
Ida Costansa Tamaela ${ }^{1}$, Patresya Apituley ${ }^{2}$, Eldaa Crystle Wenno ${ }^{3}$ \\ Pendidikan Bahasa Jerman, Fakultas Keguruan dan Ilmu Pendidikan \\ email : idatamaela@yahoo.com
}

\begin{abstract}
ABSTRAK
Tujuan kegiatan webinar dengan tema Interkulturelle Landeskunde yang dilakukan secara virtual atau daring ini adalah untuk memberikan informasi bahwa betapa pentingnya sebuah komunikasi lintas budaya dalam membangun sebuah hubungan yang baik dengan individu atau masyarakat berlatar belakang yang berbeda. Kegiatan webinar ini diikuti oleh mahasiswa semester 2 yang mengambil mata kuliah Interkulturelle Landeskunde berjumlah 18 Orang dan para siswa SMA/SMK, yaitu dari SMAN 9 Ambon, SMAN 4 Maluku Tengah, SMAN 1 Seram Bagian Barat, SMAN 44 Maluku Tengah dan SMKS Pariwisata Pamahanunusa di Masohi, seluruhnya berjumlah 62 orang. Metode yang digunakan dalam kegiatan webinar ini adalah penyajian materi, tanya jawab, pengisian angket yang disebarkan pada saat webinar berlangsung dan pemutaran video tentang Jerman dan pengetahuan bahasanya. Angket yang disebarkan berisikan pertanyaan yang berhubungan dengan materi yang diberikan oleh para narasumber. Pada akhir kegiatan diadakan kompetisi adu tepat dan cepat berupa quiz bagi para siswa. Siswa yang dapat menjawab dengan cepat dan tepat diberikan hadiah berupa pulsa data. Pelaksanaan webinar dilakukan dengan cara pemaparan materi oleh tiga narasumber asal Jerman(native speaker), dan tiga orang alumni mahasiswa Program Studi Pendidikan Bahasa Jerman yang sudah bekerja dan menetap di Jerman. Dan satu orang dosen Program Studi Pendidikan Bahasa Jerman FKIP Unpatti yang sedang studi lanjut di Dresden (Jerman). Hasil jawaban angket yang diperoleh, menunjukan bahwa kegiatan yang dilakukan berhasil membuat siswa termotivasi belajar untuk melanjutkan studi ataupun untuk bekerja di Jerman serta pentingnya pemahaman lintas budaya.
\end{abstract}

Kata Kunci : literasi informasi, lintas budaya, kesuksesan, berbasis daring 


\begin{abstract}
The purpose of this webinar with the theme Interkulturelle Landeskunde, which is conducted virtually or online, is to provide information on how important cross-cultural communication is in building a good relationship with individuals or communities with different backgrounds. This webinar activity was attended by 2nd semester students who took Interkulturelle Landeskunde, numbered 18 peoples and high school or vocational students, namely from SMAN 9 Ambon, SMAN 4 Maluku Tengah, SMAN 1 Seram Bagian barat, SMAN 44 Maluku Tengah, and SMKS Tourism Pamahanunusa in Masohi, a total of 62 peoples. The methods used in this webinar activity are the presentation of material, questions, and answers, filling out questionnaires distributed during the webinar, and playing videos about German and its language knowledge. The questionnaire distributed contained questions related to the material provided by the speakers. At the end of the competition, there is a quick and precise competition in the form of a quiz for students. Students who can answer quickly and accurately are given prizes in the form of credit data. The webinar was carried out by presenting material by three German speakers, and three alumni of German Language Education Study Program students who were already working and living in Germany. And one lecturer of the German Language Education Study Program FKIP Unpatti who is currently studying further in Dresden (Germany). The results of the questionnaire answers obtained showed that the activities carried out succeeded in making students learn to continue their studies or work in Germany as well as important cross-cultural understanding.
\end{abstract}

Keywords: information literacy, cross-cultural, success, online based

\title{
1. PENDAHULUAN
}

Ilmu pengetahuan dan teknologi (IPTEK) di zaman modern ini berkembang pesat, sehingga sangat berpengaruh terhadap semua lapisan masyarakat dalam berbagai aspek kehidupan. Hampir semua peralatan yang digunakan dalam kehidupan tidak manual lagi, melainkan sudah digital. Begitupun juga dengan berbagai informasi yang diperoleh sebagian besar sudah melalui digital. Hal ini sejalan dengan pendapat Blas (dalam Sujana \& Rachmatin, 2019) bahwa perkembangan informasi yang sangat pesat merupakan salah satu keuntungan tersendiri bagi semua orang yang terlibat dalam pembelajaran. Literasi informasi menguraikan bahwa siswa yang memiliki literasi informasi akan dapat mengidentifikasi dan menentukan kebutuhan akan informasi, mencari informasi, mengevaluasi informasi, mengatur informasi, dan mengkomunikasikan informasi sedemikian rupa untuk menjawab dan mengatasi berbagai kebutuhan yang dihadapi. Subekt et al., (2018) menambahkan bahwa perubahan dunia kini tengah memasuki era revolusi industri 4.0, di mana pola kehidupan manusia telah berbasis informasi. Dengan demikian, menyiapkan lulusan yang berkualitas 
dan mampu bersaing secara global, serta menguasai perkembangan teknologi merupakan hal yang penting bagi masa depan suatu negara.

Dengan adanya perkembangan teknologi dan literasi informasi saat ini telah terbuka lebar kesempatan dan peluang bagi generasi Milenial untuk bekerja di Jerman. Negara Jerman membutuhkan banyak tenaga terampil di bidang Kesehatan, Hospitality dan Industri. Kesempatan ini menjadi peluang yang sangat bagus, namun hal ini terdapat syarat yang perlu diikuti yaitu kemampuan bahasa Jerman Level B1 - B2. Bahkan ada beberapa bidang pekerjaan di Jerman yang mensyaratkan kemampuan bahasa level C1/C2. Bekerja di Jerman artinya, ada kesempatan untuk ijin tinggal di Jerman. Dilihat dari syarat yang ada untuk dapat tinggal di sana, selain menguasai bahasa Jerman dibutuhkan juga pengenalan budayanya. Dengan kata lain, belajar bahasa tidak cukup jika yang diajarkan hanya meliputi keterampilan menyimak, berbicara, membaca dan menulis, atau belajar kosa kata dan gramatiknya, sedangkan aspek budayanya seringkali dilupakan atau diabaikan untuk diajarkan.

Timbul pertanyaan, bagaimana komunikasi dapat berjalan dengan lancar dan baik, jika aspek budayanya diabaikan ? Sebagai salah satu contoh, adalah jarak hubungan sosial dalam berkomunikasi. Untuk menghindari salah paham tentu hal tersebut perlu dipelajari agar dalam berkomunikasi tidak terjadi salah paham. Seperti Intime Distanz bahasa yang digunakan adalah Duzen artinya bahasa yang digunakan dalam suasana santai, dengan menyapa menggunakan kata $D u$ (kamu) dan dapat berpelukan saat bertemu, beda pada jarak sosial, yang resmi (Gesellschaftliche Distanz) bahasa yang digunakan disini adalah resmi dan berjabat tangan dengan saling menatap. Dengan kata lain, fakta ini berkaitan dengan kesantunan baik dalam berbahasa maupun bertindak. Hal ini sejalan dengan hasil penelitian (Lestuny \& Wenno, 2021: 24) bahwa kesantunan berbahasa merupakan aspek penting dalam komunikasi lisan karena dapat menghindari kesalahpahaman karena perbedaan budaya serta belajar bahasa asing, khususnya bahasa Jerman, seharusnya tidak hanya fokus pada penguasaan tata bahasa dan kosakata tetapi juga pada kesopanan. Sehingga mahasiswa memiliki kesempatan untuk berlatih menggunakan tuturan komunikatif yang mengandung unsur kesantunan.

Berdasarkan contoh uraian di atas, maka diadakan webinar untuk menginformasikan betapa pentingnya dipelajari aspek lintas budaya bagi peserta didik, khususnya yang mempunyai rencana ke Jerman. Pemahaman lintas budaya (cross culture understanding) dan kemampuan adaptasi budaya (cultural adaptability) menginisiasi sebuah interaksi komunikasi dan adaptasi untuk menciptakan makna dan pemahaman sebab "komunikasi lintas budaya berbicara tentang pengamatan fenomena dan menyaring unsur-unsur budaya yang menghasilkan perilaku spesifik" Cambie \& Ooi (2009) (dalam Lustyantie \& Arung, 2020 : 98). Jika tidak, transfer makna dan pemahaman (pengetahuan) akan menjadi suatu yang nihil dan oleh karenanya, kita perlu memahami bahwa "perbedaan latar belakang linguistik dan budaya dapat menghasilkan kesalahpahaman yang signifikan karena hal itu 
menyiratkan aturan interaksi yang berbeda dan penggunaan istilah linguisik yang berbeda untuk menyampaikan makna" Soler \& Jorda (dalam Lustyantie \& Arung, 2020 : 98).

Selain itu pemahaman akan lintas budaya ini juga perlu dilakukan untuk menghindari munculnya disinformasi yang terjadi saat ini pada generasi millennial. Pratiwi \& Asyarotin (2019) berpendapat bahwa munculnya fenomena disinformasi yang terjadi saat ini pada generasi millennial disebabkan sikap mudah percaya pada informasi yang diperoleh tanpa melihat kebenarannya atau mencari dulu dari mana sumbernya. Akhirnya generasi millennial tidak memiliki kemampuan menganalisis dalam menggunakan informasi. Hasnadi (2019) menambahkan bahwa kegiatan literasi di kalangan mahasiswa masih tergolong rendah kalau dilihat dari aktivitas mahasiswa dalam kegiatan akademik dan non akademik, dan belum adanya prestasi yang ditunjukkan oleh mahasiswa dalam kegiatan-kegiatan literasi. Artinya bahwa para peserta didik baik siswa maupun mahasiswa perlu diberikan informasi terkait pentingnya pemahaman lintas budaya. Disamping itu peserta didik dapat diberikan stimulus melalui media digital seperti menonton video atau iklan TV yang mengandung unsur budaya. Sebagai contoh, salah satu mata kuliah Program Studi Pendidikan Bahasa Jerman yang mempelajari lintas budaya adalah mata kuliah “Interkulturelle Landeskunde”. Dalam mata kuliah ini, dosen telah menerapkan media pembelajaran berbasis digital yakni mahasiswa menonton iklan TV Supermarket Jerman untuk mengetahui tentang budaya serta penggunaan Bahasa dalam konteks berbelanja di Jerman. Menurut hasil penelitian yang dilakukan oleh (Wamese et al., 2021) bahwa fungsi referensial ditekankan dalam iklan TV Supermarket. Artinya bahwa informasi yang diberikan merujuk pada suatu fakta atau referensi yang jelas sehingga dapat mencerminkan unsur budaya dalam hal ini adalah budaya orang Jerman. Sehubungan dengan pemahaman lintas budaya maka peserta didik juga harus mampu mengingat dan memahami unsur-unsur budaya yang dipelajari. Salah satunya adalah dengan menerapkan juga game edukasi untuk merangsang daya ingat peserta didik dalam memahami lintas budaya. Salah satu permainan yang dapat diterapkan adalah permainan monopoli. Menurut (Luarmasse, 2021 : 55) permainan monopoli dalam pembelajaran bahasa Jerman dapat membawa pengaruh yang besar bagi daya ingat siswa, dimana dalam bermain monopoli semua siswa yang terlibat dalam permainan dituntut untuk berbicara atau menjawab pertanyaan-pertanyaan yang ada dalam papan monopoli. Dengan kata lain, daya ingat peserta didik akan pemahaman lintas budaya dapat dilatih agar kedepannya tidak terjadi disinformasi atau kesalahpahaman.

Selain menerapkan media pembelajaran yang tepat di kelas, tim mata kuliah Interkulturelle Landeskunde melakukan kegiatan Pengabdian Kepada Masyarakat berupa acara Webinar Literasi Informasi dengan melibatkan beberapa pembicara dari Jerman yang berprofesi sebagai guru, dokter, ahli elektro yang sudah memiliki pengalaman sebagai orang asing di Jerman untuk meningkatkan motivasi peserta didik dalam memahami pemahaman lintas budaya serta meningkatkan literasi peserta didik. Selain itu, para alumni Program Studi Pendidikan Bahasa Jerman Universitas Pattimura yang sudah bekerja dalam berbagai profesi di Jerman, yaitu sebagai perawat, chef, dan guru dan yang sementara studi lanjut S2 dibidang 
hukum, untuk dapat berbagi pengalaman mereka di Jerman. Untuk menambah wawasan tentang dunia pendidikan di Jerman, salah satu dosen Prodi Bahasa Jerman yang sedang studi lanjut S3 di Jerman pun ikut membagikan informasi dan pengalamannya di Jerman. Adapun kegiatan Pengabdian kepada Masyarakat dilakukan secara daring, dengan tujuan agar para siswa dan mahasiswa dapat termotivasi untuk memperdalam pengetahuan budaya Jerman. Dan bermanfaat bagi guru untuk dapat menerapkannya dalam pembelajarannya. Berikut ini adalah flyer daripada kegiatan webinar beserta narasumbernya dan foto kegiatan:

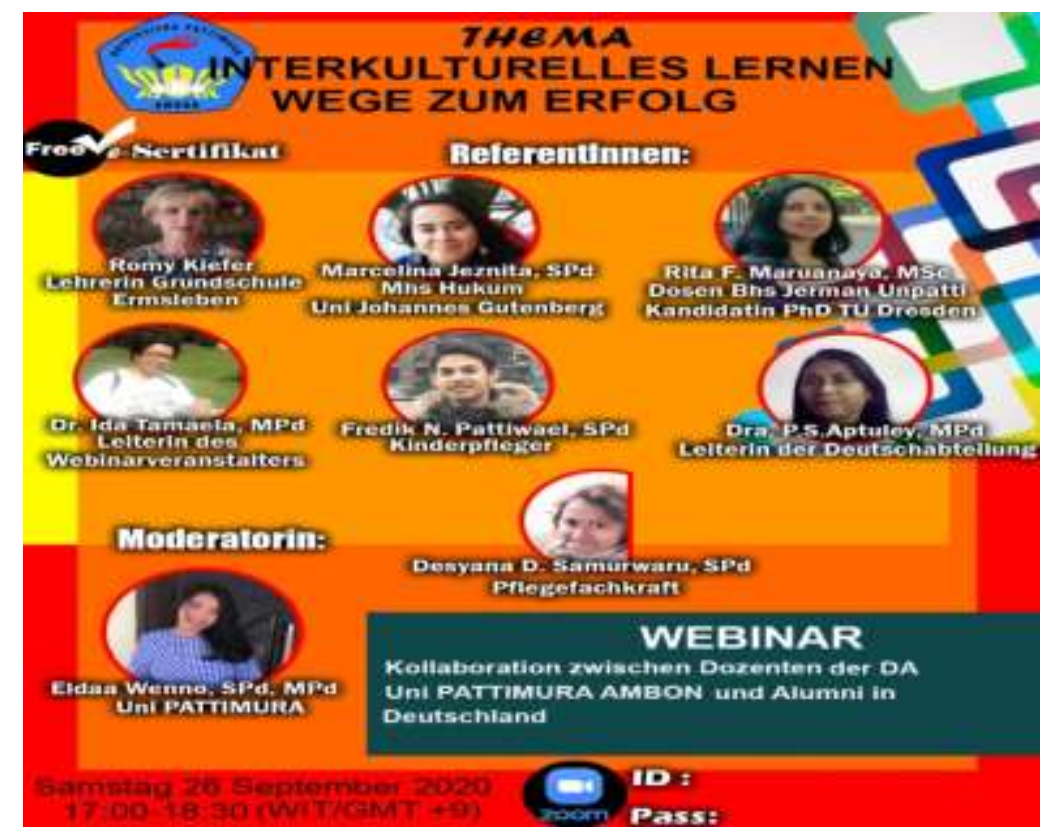

Gambar 1. Flyer Webinar

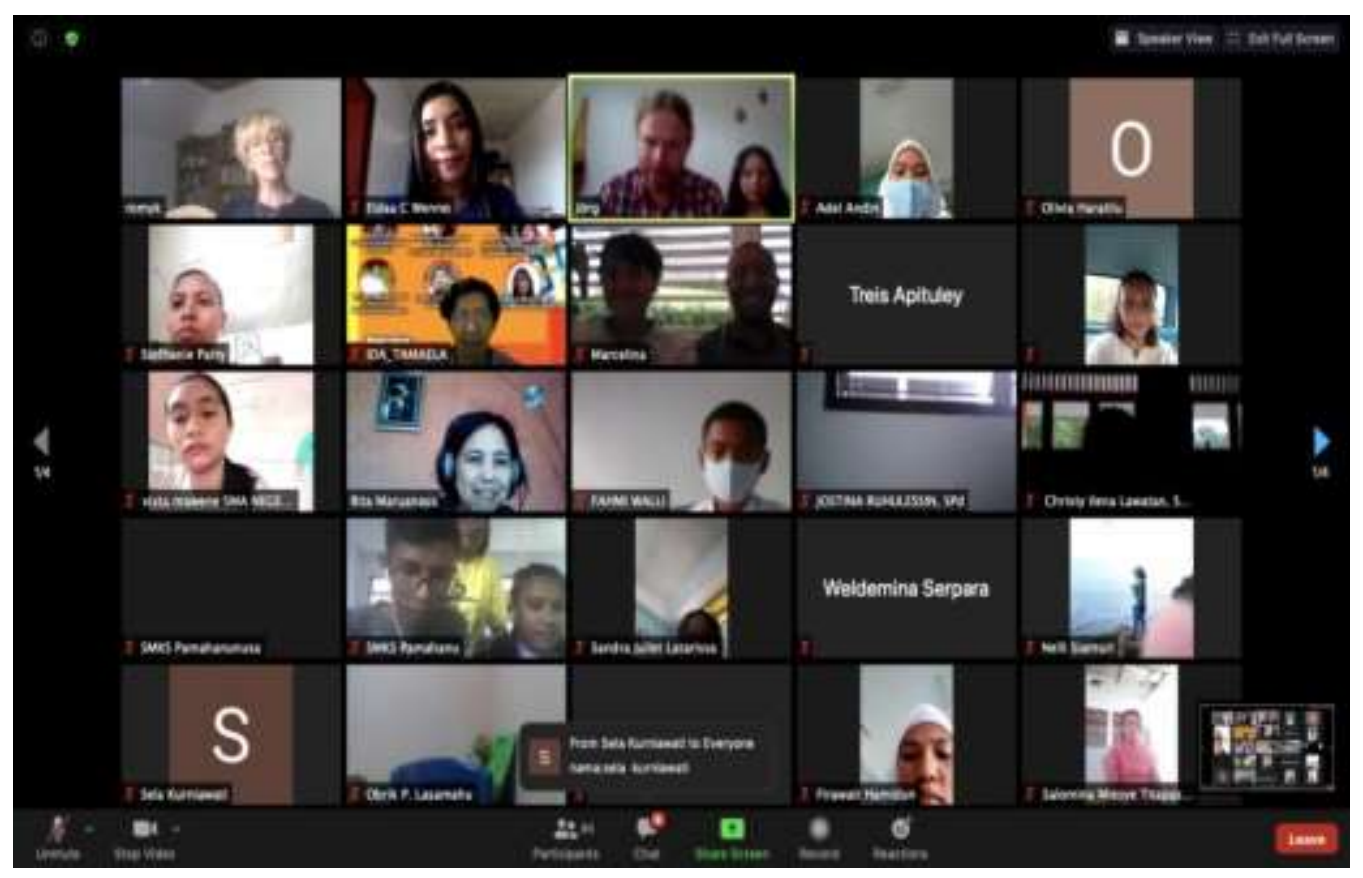


Gambar 2. Dokumentasi

\section{METODE PELAKSANAAN}

Tujuan Pengabdian Kepada Masyarakat dengan tema Interkulturelle Landeskunde adalah "Betapa pentingnya sebuah komunikasi untuk membangun sebuah hubungan yang baik". Sebuah hubungan komunikasi yang baik akan membuat suatu hubungan akan semakin erat dan juga sebaliknya sangat fatal apabila komunikasi tidak berjalan dengan efektif dampak yang sangat di timbulkan sungguh akan merugikan. Sasaran dalam kegiatan Pengabdian Kepada Masyarakat adalah siswa dan guru bahasa Jerman di SMAN 9 Ambon, SMAN 4 Maluku Tengah, SMAN 1 Seram Bagian Barat, SMAN 44 Maluku Tengah dan SMKS Pariwisata Pamahanunusa di Masohi (Maluku Tengah) pada hari Sabtu, 26 September 2020.

Kegiatan ini dalam bentuk pertukaran literasi Lintas budaya berbasis daring. Ada penjelasan materi tentang pemaparan informasi budaya di Jerman sesuai dengan materi yang disiapkan. Simulasi terhadap materi dalam bentuk tips dan trik serta contoh langsung untuk beradaptasi dengan budaya Jerman yang dilakukan dengan cara diskusi atau tanya jawab, pemutaran video pembelajaran tentang budaya Jerman dan pengetahuan bahasanya. Sedangkan praktik materi ditujukan untuk menumbuhkan pemahaman tentang pentingnya belajar budaya Jerman melalui pengalaman langsung sesuai dengan informasi yang diberikan dengan cara mengisi angket yang telah disediakan. Kegiatan akhir adalah Quiz singkat bagi para peserta didik. Kegiatan ini dilakukan berdasarkan kebutuhan yang ada di lapangan. Dengan adanya peluang ke Jerman dan memperoleh beasiswa di Jerman untuk bekerja di dunia industri.

\section{HASIL DAN PEMBAHASAN}

Kegiatan Pengabdian masyarakat memberikan harapan baru untuk transfer pengetahuan dan pertukaran literasi lintas budaya dari para narasumber. Melalui kegiatan ini, diharapkan pengetahuan tentang budaya dapat diperoleh, dan dipraktekkan dalam proses belajar mengajar sesuai dengan kebutuhan guru dan siswa. Angket yang disebarkan kepada 80 peserta didik memuat 22 butir soal yang berkaitan dengan pemahaman lintas budaya antara budaya asal dan budaya Jerman. Adapun butir-butir soal terdapat 8 butir soal positif dan 12 butir soal negatif sehingga dapat mengasah kemampuan berpikir kritis peserta didik dan mereka juga mampu mengenali perbedaan budaya Jerman dan Indonesia, mencermati beberapa aspek budaya Jerman dan Indonesia yang kemungkinan dapat menyebabkan perbedaan. Berdasarkan analisis data terhadap angket yang telah disebarkan kepada para peserta didik setelah mengikuti webinar, diperoleh hasil sebagai berikut: 


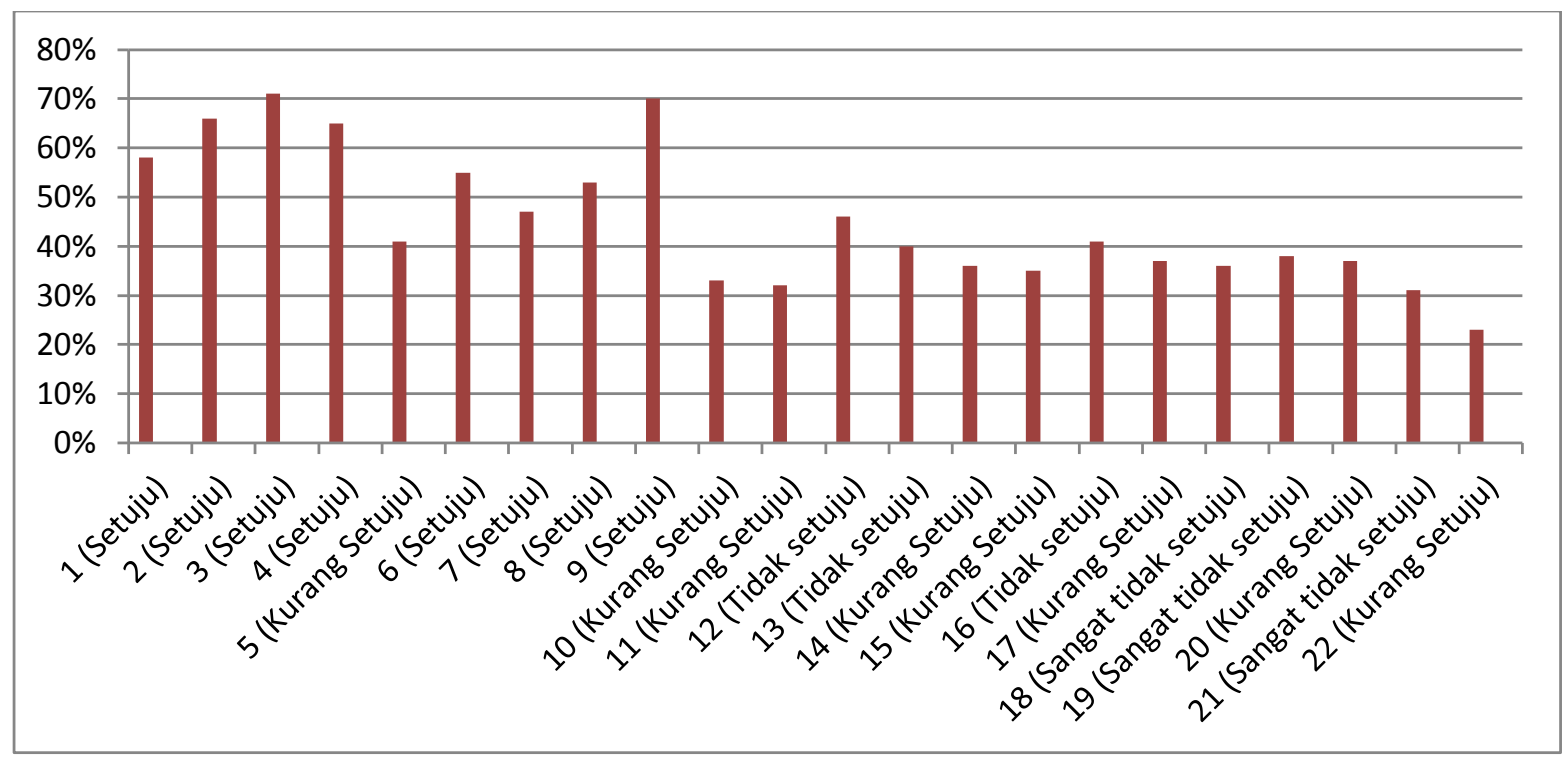

Grafik 1. Presentase Jawaban Angket

Setelah diidentifikasi dan dianalisis hasil data pada Grafik 1. menjelaskan bahwa setelah peserta didik mengikuti kegiatan webinar yang dilaksanakan oleh Dosen pengampu mata kuliah Interkulturelle Landeskunde di Program Studi Pendidikan Bahasa Jerman yang berkolaborasi dengan para Alumni yang tinggal di Jerman, rata-rata $60 \%$ presentase para siswa baru dengar kata Interkulturelle saat mau mengikuti webinar ini, selanjutnya $71 \%$ siswa telah mengetahui bahwa Interkulturelle adalah lintas budaya, dan 65\% siswa setuju bahwa selain belajar bahasa Jerman di kelas, guru harus mengajarkan juga tentang budaya Jerman karena lintas budaya merupakan tata cara kehidupan yang perlu dipelajari setiap siswa di era globalisasi saat ini. Para siswa juga setuju bahwa tujuan utama mempelajari Lintas budaya adalah untuk mengetahui cara kehidupan sehari-hari satu budaya, untuk mengetahui jenis makanan budaya negara lain dan dapat mempersiapkan seseorang dalam membangun hubungan sosial antarbudaya baik di lingkungan tempat tinggal maupun di tempat pekerjaan, seseorang juga harus tepat waktu dan jika ingin bertamu ke rumah orang lain, perlu membuat janji terlebih dulu.

Hasil data menunjukan bahwa peserta didik telah memahami pentingnya pemahaman lintas budaya. Hal ini juga dibuktikan dengan data pada kolom komentar dari angket yang disebarkan dimana para siswa berpendapat bahwa mereka akan belajar lebih banyak tetang kebudayaan orang jerman dan akan berusaha agar bisa dengan cepat belajar serta beradaptasi dengan budaya Jerman. Selain itu, mereka berpendapat bahwa jika mereka berada di suatu tempat, mereka harus memahami, menghargai dan beradaptasi dengan budaya setempat tetapi dengan tidak menghilangkan budaya yang mereka miliki sebelumnya. Artinya, tidak hanya mempelajari bahasanya tetapi harus mempelajari budaya dari negara tersebut dan dalam hal berbusana setiap orang mempunyai cara berbusana yang berbeda-beda dan beraneka ragam jadi cara berbusana menurut budaya Indonesia adalah hal yang salah akan tetapi menurut budaya luar (budaya Jerman) itu adalah cara berbusana yang telah terapkan 
dalam kehidupan sehari-hari. Masing-masing negara dengan kebudayaannya sendiri dan tentunya berbeda dengan negara lain, misalnya cara berpakaian dan adat istiadat yang berbeda. Dengan kata lain, menghargai budaya tidak hanya dengan mempelajari bahasanya tetapi juga mengambil hal positif dari budaya suatu bangsa, khususnya budaya Jerman seperti ketepatan waktu dan hidup mandiri. Selanjutnya semua kebiasaan dan aktifitas yang di lakukan oleh masing masing orang itu didasarkan pada apa yang membuat mereka merasa nyaman. Sebaiknya tidak perlu saling mengomentari hal-hal yang tidak baik, karena hidup akan tidak berwarna tanpa perbedaan karena budaya di negara kita berbeda dengan budaya di negara lain (Jerman) sehingga perlu adanya rasa saling menghargai. Hal ini bermanfaat saat berkunjung, dengan beradaptasi dan mengikuti budaya atau kebiasaan di tempat yang kita datang atau kunjungi (Jerman). Selain itu, kebiasaan untuk datang tidak tepat waktu yang sudah di tentukan jadwalnya dengan tepat itu adalah suatu kebiasaan yang buruk dan hal tersebut harus di perbaiki oleh setiap orang. Di sisi lain, kita harus mempertahankan budaya meskipun telah mempelajari dan beradaptasi dengan budaya Jerman di era globalisasi. Peserta didik harus mengikuti webinar bahasa Jerman agar bisa menjadi bekal dan pedoman bagi mereka ke masa yang akan datang dan dapat mewujudkan apa yang mereka inginkan yaitu belajar dan bekerja di Jerman.

\section{KESIMPULAN}

Hasil dan pembahasan menunjukan bahwa dengan mengikuti kegiatan webinar Interkulturelle ini, dapat disimpulkan bahwa, materi yang diberikan sangat bermanfaat. Hal ini terlihat dengan adanya antusias peserta didik maupun guru saat mengajukan pertanyaan, mengisi angket dan memberikan komentar sehingga peserta didik mampu untuk mengenali, menghargai perbedaan budaya Jerman dan Indonesia, dan mencermati beberapa aspek budaya Jerman dan Indonesia yang kemungkinan dapat menyebabkan perbedaan. Selain itu, kegiatan webinar menjadi sebuah motivasi bagi peserta didik yang ingin belajar baik melanjutkan studi ataupun untuk bekerja di Jerman. Terlihat juga ketika diadakan quiz atau game edukasi terkait materi budaya yang disampaikan siswa merasa termotivasi untuk menjawab secara rebutan walaupun sudah ditertibkan. 


\section{REFERENSI}

Hasnadi, H. (2019). Membangun Budaya Literasi Informasi pada Perguruan Tinggi. Prosiding SEMDI-UNAYA (Seminar Nasional Multi Disiplin Ilmu UNAYA), 3(1), 610-620.

Lestuny, C., \& Wenno, E. C. (2021). The Students Perception Of Language Politeness Based Teaching Materials In Speaking Skills At German Language Department Pattimura University Ambon. PEJLaC: Pattimura Excellence Journal of Language and Culture, 1(1), 19-25.

Luarmasse, N., Serpara, H., \& Marantika, J. (2021). Pengaruh Media Pembelajaran Permainan Monopoli Terhadap Keterampilan Berbicara Siswa Sma N 5 Kabupaten Kepulauan Tanimbar. J-EDu : Journal Erfolgreicher Deutschunterricht, I(2 SE-Articles). https://doi.org/10.30598/JEDu.1.2.48-56

Lustyantie, N., \& Arung, F. (2020). Pembelajaran Inovatif Bahasa dan Sastra: Mengembalikan Prinsip Bahasa dan Sastra Sebagai Cara Berpikir Inovatif (1st ed.). Deepublish Publisher.

Pratiwi, A., \& Asyarotin, E. N. K. (2019). Implementasi literasi budaya dan kewargaan sebagai solusi disinformasi pada generasi millennial di Indonesia. Jurnal Kajian Informasi \& Perpustakaan, $7(1), 65-80$.

Subekt, H., Taufiq, M., Susilo, H., Ibrohim, I., \& Suwono, H. (2018). Mengembangkan literasi informasi melalui belajar berbasis kehidupan terintegrasi stem untuk menyiapkan calon guru sains dalam menghadapi era revolusi industri 4.0: revieu literatur. Education and Human Development Journal, 3(1).

Sujana, A., \& Rachmatin, D. (2019). Literasi digital abad 21 bagi mahasiswa PGSD: apa, mengapa, dan bagaimana. Current Research in Education: Conference Series Journal, 1(1), 3.

Wamese, E., Tomasouw, J., \& Karuna, K. (2021). Language Functions in German Supermarket TV Commercials. J-EDu: Journal Erfolgreicher Deutschunterricht, 1 (1 SE-Articles). https://doi.org/10.30598/J-EDu.1.1.1-11 